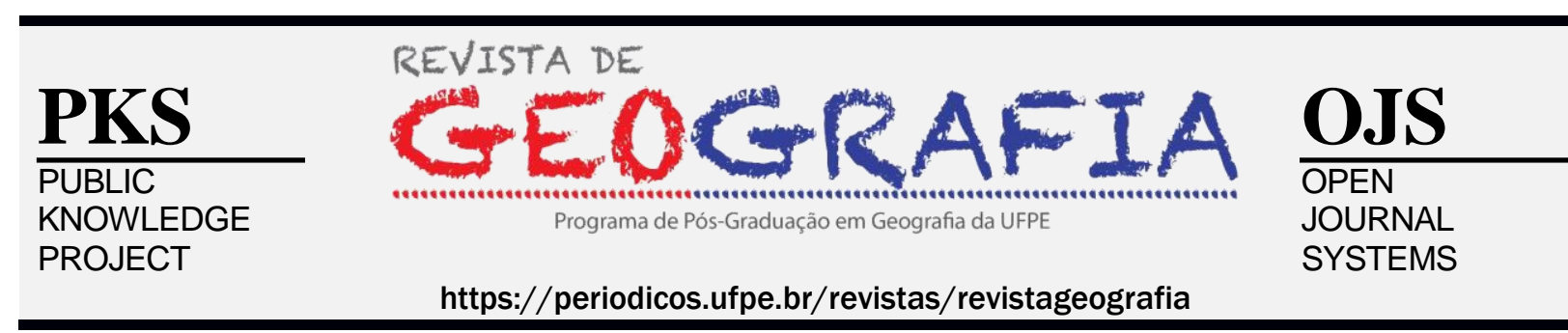

\title{
O OBJETO EM FUGA: ALGUMAS REFLEXÕES EM TORNO DO CONCEITO DE REGIÃO
}

\author{
José Roberto Henrique Souza Soares ${ }^{1}$ \\ ${ }^{1}$ Universidade Federal de Pernambuco (UFPE).E-mail: roberto.henriquesoares@ufpe.br
}

Artigo recebido em 05/09/2018 e aceito em 09/11/2018

DOI:

\begin{abstract}
RESUMO
O trabalho abordado nesta rápida analise crítica foi elaborado com a finalidade de discutir epistemologicamente o uso dos conceitos de Região e Regionalização por historiadores que se debruçam sobre o campo da Historiografia Regional. Nesta perspectiva o autor discute as possibilidades e como tais pesquisadores devem conceber e discutir os fenômenos oriundos da regionalização dos espaços. Tal proposta se baseia numa abordagem foucaultiana, em que a categoria Região é percebida como um objeto idealizado e planejado, utilizado apenas para segregrar socioeconomicamente os espaços em defesa dos interesses de uma parte minoritária da sociedade. Este texto serve para compreendermos como a organização espacial dos territórios podem ser utilizadas para diversas finalidades, mas no entanto, devem ser compreendidas e utilizadas para proporcionar a integração e valorização da diversidade.
\end{abstract}

Palavras-chave: Região; Regionalização; Historiografia.

\section{THE PURPOSE OBJECT: SOME REFLECTIONS AROUND THE CONCEPT OF REGION}

\begin{abstract}
The work covered in this short critical analysis was elaborated with the purpose of discuss the epistemological use of the concepts of Region and Regionalization by historians who study the Regional Historiography field. In this perspective the author discusses the possibilities and how such researchers must conceive and discuss the phenomena originating from the regionalizations of spaces. This proposal was based on a Foucaultian approach, in which the Region category is perceived as an idealized and planned object, used only to segregate socioeconomically spaces in defense of a minority part interests of the society. This paper serves to understand how spatial organization of territories can be used for various purposes, but however, they must be understood and used to provide the integration and appreciation of diversity.
\end{abstract}

Keywords: Region; Regionalization; Historiography. 


\section{RESENHA}

A obra aqui analisada se constitui como um artigo científico publicado no ano de 2008, na Revista Fronteiras da Universidade Federal da Grande Dourados (UFGD). Este trabalho foi elaborado pelo historiador Dr. Durval Muniz de Albuquerque Júnior, autor do famoso livro "A Invenção do Nordeste", uma referência singular para os estudos regionais com base filosófica foucaultiana. Em "O objeto em fuga: algumas reflexões em torno do conceito de Região", o autor busca atender as necessidades e perspectivas de um grupo de historiadores que se debruçam sobre a chamada "Historiografia Regional", conhecida por muitos como história regional. Por conseguinte, o trabalho no qual nos debruçamos não foi elaborado com o objetivo de discutir a categoria geográfica conhecida como Região, mas, para discorrer sobre os estudos das Regiões ou de Regionalismos ${ }^{2}$, desenvolvidos por historiadores.

A maior parte das reflexões sobre o conceito de Região, elencadas no artigo definem esta categoria científica de maneira oposta ao que alguns geógrafos, como Haesbaert (2010), Lencione (2009), Santos (2014), Lacoste (2012), Castro, Gomes e Corrêa (2000), consideram. Para Albuquerque Júnior (2008), este conceito é concebido como algo fixo, já dado, evidente e não-problemático. Identificada como uma realidade imaterial, a Região aparece de acordo com a obra, como uma fonte de problemas que podem vir a ser objetivos de analise para os estudiosos, porém a categoria em si não é passível de estudos.

Assim o autor legitima o regionalismo como argumento para todo saber que é produzido em nome do conceito de Região. Um exemplo desta negação da categoria geográfica em favor do idealismo defendido por Albuquerque Júnior (2008) é sua mais famosa obra: A Invenção do Nordeste, editada pela quinta vez no ano de 2011. Neste livro o autor defende a tese de que a Região Nordeste é apenas uma "invenção", criada a partir de concepções e definições que foram divulgados durante os séculos XIX e XX. Tal tese

\footnotetext{
${ }^{1}$ Campo teórico e metodológico da História que busca compreender os fenômenos delimitadores dos espaços em aspectos sociais, políticos e econômicos. De acordo com a descrição da Revista de História Regional (UEPG), esta área busca discutir a historicidade das práticas sociais e culturais, das construções discursivas e da produção de sentidos que, no tempo e no espaço, resultam em distintos processos de regionalizações.

2 Geograficamente a categoria de analise Região apresenta diferença de significado em relação ao Regionalismo. A Região, assim, é concebida como produto intelectual ou organizacional de homogeneização dos espaços, diferenciando-os no território. De outra forma, o Regionalismo se dá como uma ideologia, disseminada pelas classes dominantes com fins de manutenção do poder.
} 
desconsidera, no entanto, todos os esforços empenhados nas últimas décadas em torno do desenvolvimento social e econômico desta parcela do território brasileiro.

Para compreendermos a concepção defendida pelo autor, precisamos recorrer ainda a um estudo posterior elaborado por Vesentini (2012), em que este geógrafo utiliza a mesma divisão territorial, o Nordeste, para definir o conceito de Região através de três concepções analíticas e metodológicas distintas, as quais o autor preferiu chamar como Registros. Desta forma, a Região pode ser compreendida por meio da definição desenvolvida durante muitos séculos na Geografia e que teve como principal precursor o francês Vidal de La Blache, a qual Vesentini (2012), definiu como tradicional. Este primeiro registro compreende a Região como algo natural, definido por determinadas ocupações humanas em partes específicas do espaço geográfico.

O segundo registro é definido pelo autor como moderno, que se constitui pela divisão inter-regional do trabalho, dando ênfase a economia e sua capacidade de dinamização dos espaços, com forte tendência marxista. De outra forma, o terceiro registro de percepção das Regiões parte do pressuposto que as mesmas são construídas em função de interesses materiais e ideológicos de alguns, poucos, grupos dominantes. Esta última concepção é definida como pós-moderna e tem sua base fundamentada nas perspectivas foucaultianas.

Neste sentido, Albuquerque Júnior (2011) considera a Região sob as concepções pósmodernas, conforme a perspectiva apresentada por Vesentini (2012). Baseado no alicerce foucaultiano, Albuquerque Júnior (2011) considera que as relações de poder determinaram o que ficou conhecido como Nordeste. Para o autor esta Região brasileira surgiu como resultado das ideias nacionalistas do século XIX, bem como pelo crescimento da indústria e da urbanização na antiga Região Sul do país. Assim foram se criando dois países distintos, um desenvolvido e muito ligado aos modelos europeus, enquanto o outro se distanciava pelo atraso, pelos costumes arcaicos e exóticos.

Por meio da literatura, de registros jornalísticos e obras literárias, o Nordeste foi inventado. Para o autor, os elementos culturais disseminaram uma ideia de Nordeste que acabou o consolidando como nós conhecemos hoje, além de criar os estereótipos, as músicas, relatos literários e peças teatrais, estes elementos auxiliaram a construir a dicotomia no país. Com a aceitação e contribuição dos próprios nordestinos, que migravam para outras Regiões, servindo como mão de obra a ser explorada pelas grandes obras e companhias do Sul brasileiro, os elementos culturais consolidaram a imagem de atraso e improdutividade do Nordeste brasileiro. 
Sob esta perspectiva, Albuquerque Júnior (2008) no artigo analisado, defende o fim da Região por parte dos historiadores. O autor chega a afirmar que "o historiador da região é aquele que investe em seu desmonte, em seu desmantelamento pedra a pedra" (ALBUQUERQUE JÚNIOR, 2008. p. 64). Tal posicionamento só é compreensível, uma vez que entendemos o aporte teórico e metodológico utilizado para definir o conceito de Região, como algo idealizado e planejado, utilizado apenas para segregrar socioeconomicamente os espaços. Assim, é imprescindível que compreendamos as diferentes concepções que permeiam as Regiões, conforme destaca Vesentini (2012), tais registros filosóficos dão materialidade a categoria geográfica Região.

A crítica crucial realizada pelo autor no artigo estudado, bem como por quase todos que observam a Região sob o espectro foucaultiano recai nas práticas que são divulgadas em nome deste conceito, as quais denominam-se Regionalismo. A difusão de práticas estereotipadas e que nada acrescentam ao desenvolvimento econômico e social dos territórios não devem ser consideradas. Por tanto é indispensável que se compreenda a proposta discorrida no texto como um elemento que busca ultrapassar os preconceitos e auxiliar na construção de territórios justos e igualitários, em que as diferenças possam conviver cordialmente.

Sob a matriz epistemológica da Geografia, a Região adquire relevância singular por se tratar de uma categoria que visa, de acordo com Haesbaert (2010), conceber analises e propostas integradoras. Tal concepção se contrapõe a ideia elaborada por Albuquerque Júnior (2008), tendo em vista que para este, as práticas disseminadas em nome da região segregam e distanciam mais os pares do que cumpre sua função primordial de aproximação política e econômica dos espaços.

Na obra analisada, Albuquerque Júnior (2008), define a Região e suas formas de disseminação com o mesmo rigor com que Rafestin (1993) conceituou as relações de poder que estão implícitas no Território. Assim, no artigo abordado, a Região assume as características desta outra categoria geográfica, uma vez que tal conceito também é utilizado para definir estratégias de organização política e de dominação espacial. Nesta perspectiva, as regiões são concebidas como acontecimentos históricos, políticos, militares e diplomáticos, frutos de disputas e conflitos que eclodem na dominação de alguns poucos grupos, sobre os demais

Na Geografia, durante muitos séculos, a Região também foi aceita como uma categoria de analise que percebia os fenômenos espaciais como agrupamento de parcelas 
homogêneas do território nacional de cada país. Paul Vidal De La Blache, foi um dos precursores e maior disseminador desta concepção na França do século XIX, Lacoste (2012), aponta que La Blache instalou na Geografia a concepção do "homem-habitante" (LACOSTE, 2012. p.59) em detrimento da função ontológica de todos os seres humanos, que os constituem como seres sociais. Este homem voltado apenas para sua habitação, seu território e sua identidade abandona as formas sociais de organização e impulsiona movimentos regionalistas. A própria Geografia Regional, difundida por Vidal De La Blache, proporciona a disseminação de Regionalismos, ao descreverem dicotomicamente os aspectos que diferenciam os espaços, e os tornam como territórios diferenciados pela regionalização. Esquecendo que esta divisão é algo passível de questionamentos, divergências e sobretudo campo para novas reformulações.

No entanto na atualidade, de acordo com Lencione (1999) as Regiões se constituem principalmente como uma forma de organização estratégica a qual ela enuncia como técnicaoperacional. Esta colocação destina à categoria geográfica como uma classe teórica que serve para classificar os espaços, por meio das regularidades. Não importa apenas destacarmos as condições similares entre os espaços, a Região serve muito mais para que consigamos uniformizar as áreas. Mas como separar e criar investimentos para áreas que são regulares, porém apresentam problemas na maioria das vezes distintos?

Esta categoria, é definida por Haesbaert (2010) como um arte-fato, uma vez que o regional é um fenômeno capaz de criar a realidade e se auto-criar simultaneamente. Essa realidade é que dá sentido à categoria geográfica aqui analisada. Além de ser um fato planejado e difundido como estratégia de organização política é uma forma de organização socioespacial, que conjuntamente visa reafirmar as identidades locais, num contexto de mundialização das potencias econômicas do planeta. Oliveira (1981) em um trabalho de cunho econômico, defende que o planejamento estratégico das Regiões, é um dos fatores primordiais para que ocorra o desenvolvimento almejado aos lugares.

Corroborando com este pensamento, Santos (2014) define as regiões como a área de ação de um grupo específico com interesses similares, para este autor os arranjos regionais não têm mais a estabilidade "histórica" que possuíam na velha tradição francesa clássica, em que as regiões eram consideradas como resultado do duradouro processo de formação dos gêneros de vida e das paisagens deles decorrentes, como foi estruturado por Vidal De La Blache. O comando atual das mediações regionais é dado pela lógica das grandes empresas, partindo delas os principais nexos da organização regional do mundo atual. Esta categoria 
geográfica usualmente, para Castro, Gomes e Correia (2000) é utilizada para definir os limites territoriais das similaridades, além de caracterizar os espaços de poder ou influência dos governos e das grandes empresas do capital, servindo como instrumento de organização territorial e das políticas públicas, visando o desenvolvimento econômico, baseado no sistema capitalista.

Frente a este arcabouço de ideias e divergências que formam o conhecimento científico, e aqui, em especial sobre as concepções que definem a Região, é importante ressaltarmos que o espaço geográfico é além de tudo um elemento dinâmico, que sofre influência dos diversos meios em que se insere. Portanto, os estudiosos da Região, enquanto categoria de análise, precisam estar atentos aos mecanismos de mutação, as interferências globais que são realidade em todos os espaços, e sobretudo valorizar e compreender de maneira holística os fenômenos de resistência em meio a essa crise de homogeneização global, que o capital impõe atualmente.

\section{REFERÊNCIAS}

ALBUQUERQUE JÚNIOR, D. M. O objeto em fuga: algumas reflexões em torno do conceito de região. Fronteiras: Revista de História. v. 10, n. 17. UFGD, 2008. p. 55-67 . A invenção do Nordeste e outras artes. 5 ed. São Paulo: Editora Cortez, 2011.

CASTRO, I. E.; GOMES, P. C. C.; CORRÊA, R. L. Geografia: conceitos e temas. $2^{\circ}$ ed. Rio de Janeiro. Bertrand Brasil. 2000. pp. 49-76.

HAESBAERT, R. Regional-global: dilemas da região e da regionalização na geografia contemporânea. Rio De Janeiro: Bertrand Brazil, 2010.

LACOSTE, Y. A Geografia: isso serve, em primeiro lugar, para fazer a guerra. Tradução de Maria Cecília França. Campinas-SP: Editora Papirus, 1988.

LENCIONI, S. Região e Geografia. São Paulo: Edusp, 1999.

RAFESTIN, C. Por uma Geografia do Poder. Tradução de Maria Cecília França. São Paulo: Editora Ática, 1993.

OLIVEIRA, F. Elegia para uma re (li) gião: SUDENE, nordeste. Planejamento e conflitos de classes. $3^{\text {a }}$ ed. Rio de Janeiro: Paz e Terra, 1981.

SANTOS, M. Metamorfoses do espaço habitado: fundamentos teóricos e metodológicos da geografia. 6 ed. São Paulo: Editora da Universidade de São Paulo, 2014. 
Revista de Geografia (Recife) V. 36, No.1, 2019

VESENTINI, J. W. O conceito de região em três registros. Exemplificando com o Nordeste brasileiro. Confins. Revue franco-brésilienne de géographie/Revista franco-brasilera de Geografia, n. 14, 2012. 